\title{
Lung Mechanics in Normal Infants and Infants with Congenital Heart Disease
}

\author{
GERALDINE HOWLETT \\ From the Department of Paediatrics, Institute of Diseases of the Chest, London
}

\begin{abstract}
Howlett, G. (1972). Archives of Disease in Childhood, 47, 707. Lung mechanics in normal infants and infants with congenital heart disease. The results of a study of pulmonary mechanics in 24 normal infants and 28 infants with congenital heart disease aged 1 to 32 weeks are presented. The two groups were matched for length and weight. The diagnosis of the infants with congenital heart disease varied from simple stenoses to complex septal defects and transpositions. 6 infants were studied before and after operation designed to improve their haemodynamic situation.

Pulmonary compliance and mean pulmonary resistance were measured using a pneumotachygraph, integrator, and oesophageal balloon; thoracic gas volume was measured by the plethysmographic method. Results were found to be reproducible both in the individual and within the normal group.

Thoracic gas volume in relation to weight and pulmonary resistance were normal in the infants with congenital heart disease, but the pulmonary compliance was often abnormal even when related to lung volume. The change in compliance was not simply related to pulmonary blood flow or pressure but was related to the radiological assessment of pulmonary plethora or oligaemia - the more plethoric the lower the compliance. Surgery altered both the radiological grading and the compliance appropriately. It is postulated that changes in the elastic properties of the lungs are related to changes in the pulmonary capillary blood volume.
\end{abstract}

The alteration in pulmonary haemodynamics due to various congenital cardiac malformations has been shown in previous studies on adults (Saxton et al., 1956; Davies, Williams, and Wood, 1962; Davies and Gazetopoulos, 1967), children (Wallgren, Geubelle, and Koch, 1960; Ohnishi, 1970), and experimental animals (Borst et al., 1957; Cook et al., 1959) to have an effect upon the mechanical behaviour of the lungs. The present study was undertaken to investigate this effect in neonates and infants with congenital heart disease in order to see whether measurements of lung mechanics could be used to assess the severity of the cardiac defect and to evaluate the effect of surgery.

Normal values of lung volume and mechanical behaviour are available for infants in the first week or two of life (Klaus et al., 1962; Auld et al., 1963; Cook et al., 1957; Swyer, Reiman, and Wright, 1960) but there are only a few reports of measurements made on infants beyond this age

Received 30 March 1972.
(Wallgren et al., 1960; Krieger, 1963; Phelan and Williams, 1969; Doershuk et al., 1970). Because there is a wide scatter in the normal results quoted by these workers the various parameters of lung function were also measured in a comparable group of normal infants to serve as controls.

\section{Subjects}

Normal infants. 24 normal infants were studied between the ages of 1 week and 8 weeks, 2 infants being studied twice. There was no history of any pulmonary or other complication at birth or in the postnatal period, and on the day of the study all infants were clinically normal. Eight infants were studied at the age of 1 week on the day before discharge and the others were studied at a later date when their mothers brought them back to the laboratory. Written permission was obtained from the mother in all cases, after a full explanation of the procedures involved.

Infants with congenital heart disease. 28 infants with congenital heart disease were studied and of these 21 had cardiac catheter studies within 1 to 2 weeks of 

Congenital Heart Disease

\begin{tabular}{|c|c|c|c|c|c|}
\hline Case No. & $\begin{array}{l}\text { Age } \\
\text { (wk) }\end{array}$ & $\begin{array}{l}\text { Mean Pulmonary } \\
\text { Artery Pressure } \\
\text { (mmHg) }\end{array}$ & $\begin{array}{c}\text { Pulmonary } \\
\text { Flow } \\
\left(1 / \text { min per } \mathrm{m}^{2}\right)\end{array}$ & $\underset{\text { Grading }}{X \text {-ray }}$ & Diagnosis $†$ \\
\hline $\begin{array}{l}1 \\
2 \\
3 \\
4 \\
5 \\
6 \\
7 \\
8 \\
9 \\
\\
10 \\
11 \\
12 \\
13 \\
14 \\
15 \\
16 \\
17 \\
18 \\
19 \\
20 \\
21 \\
22 \\
23 \\
24 \\
25 \\
26 \\
27 \\
28\end{array}$ & $\begin{array}{c}1 \frac{1}{2} \\
12 \\
6 \\
5 \\
2 \\
8 \\
18 \\
2 \\
3 \\
\\
7 \\
10 \\
32 \\
17 \\
17 \\
1 \\
24 \\
11 \\
1 \\
14 \\
5 \\
7 \\
6 \\
12 \\
1 \frac{1}{2} \\
3 \\
1 \\
2 \\
4\end{array}$ & $\begin{array}{c}27 \cdot 5 \\
30 \cdot 0 \\
55 \cdot 0 \\
- \\
- \\
9 \cdot 0 \\
55 \cdot 0 \\
- \\
18 \cdot 0 \\
38 \cdot 5 \\
39 \cdot 0 \\
42 \cdot 0 \\
32 \cdot 5 \\
35 \cdot 0 \\
- \\
20 \cdot 0 \\
76 \cdot 0 \\
43 \cdot 0 \\
42 \cdot 0 \\
10 \cdot 0 \\
57 \cdot 0 \\
- \\
- \\
- \\
- \\
- \\
-\end{array}$ & $\begin{array}{r}28 \cdot 0 \\
7 \cdot 3 \\
5 \cdot 6 \\
4 \cdot 7 \\
- \\
1 \cdot 4 \\
2 \cdot 9 \\
3 \cdot 4 \\
11 \cdot 6 \\
\\
4 \cdot 2 \\
9 \cdot 3 \\
17 \cdot 5 \\
11 \cdot 6 \\
7 \cdot 4 \\
3 \cdot 0 \\
4 \cdot 0 \\
2 \cdot 5 \\
11 \cdot 7 \\
1 \cdot 4 \\
4 \cdot 1 \\
10 \cdot 8 \\
- \\
- \\
- \\
- \\
- \\
-\end{array}$ & $\begin{array}{r}3 \\
2 \\
2 \\
2 \\
3 \\
-1 \\
-1 \\
0 \\
3 \\
\\
1 \\
2 \\
1 \\
2 \\
1 \\
0 \\
1 \\
3 \\
0 \\
0 \\
-1 \\
1 \\
3 \\
0 \\
0 \\
2 \\
0 \\
1 \\
0\end{array}$ & $\begin{array}{l}\text { VSD, PDA, ASD, coarctation } \\
\text { PDA } \\
\text { PDA, VSD, coarctation } \\
\text { Truncus arteriosus } \\
\text { TGA, VSD, PDA, coarctation } \\
\text { PS, ASD } \\
\text { PDA, pulmonary hypertension } \\
\text { Tricuspid atresia, VSD } \\
\text { VSD, ASD, PS, anomalous venous } \\
\text { return } \\
\text { TGA, VSD, PDA } \\
\text { MI, coarctation, common ventricle } \\
\text { Atrioventricular canal } \\
\text { VSD, PS } \\
\text { VSD } \\
\text { Mitral atresia, VSD, ASD } \\
\text { Cardiomegaly } \\
\text { VSD, PDS, coarctation } \\
\text { TGA, ASD, VSD, coarctation } \\
\text { PDA, VSD } \\
\text { PS, VSD } \\
\text { PDA, VSD, coarctation } \\
\text { VSD, PDA } \\
\text { TGA, PSD, ASD, PDA } \\
\text { PDA } \\
\text { Truncus arteriosus, VSD } \\
\text { TGA, VSD, ASD } \\
\text { VSD, PDA } \\
\text { VSD, PS }\end{array}$ \\
\hline
\end{tabular}

*-1, oligaemic; 0 , normal; 1, 2, and 3, increasing plethora. PDA, persistent ductus arteriosus; VSD, ventricular septal defect; PS pulmonary stenosis; ASD, atrial septal defect; TGA, transposition of great arteries; MI, mitral incompetence.

Note: In those infants for whom catheter data are not given, either the pulmonary artery was not entered or the diagnosis was made on clinical grounds or at necropsy.

the lung function tests, there having been no alteration in treatment between the two investigations. 6 infants were also studied before and after operations undertaken to decrease right-to-left shunting in 1 infant by relieving a pulmonary stenosis, and to decrease a left-to-right shunt in 5 others. The diagnosis varied from a simple persistent ductus arteriosus to complicated septal defects and transposition of the great arteries, and therefore could not be placed in simple groups. The details of the diagnosis and the various parameters of pulmonary haemodynamics in those infants who were catheterized are given in Table I.

\section{Methods and Calculations}

The method used in this study was similar to that described by Phelan and Williams (1969). The infant was lightly sedated with chloral hydrate $60 \mathrm{mg} / \mathrm{kg}$ fairly soon after a feed. A small latex balloon, $5.0 \mathrm{~cm}$ long, $1.8 \mathrm{~cm}$ in circumference, and containing approximately $0.2 \mathrm{ml}$ of air, was passed via the mouth to the middlethird of the oesophagus. Respiratory changes in oesophageal pressure were recorded by an S.E. Laboratories 1150/D5964 pressure transducer. The infant was then placed in a body plethysmograph of the same design as that described by Cross (1949). Siliconized putty was used to seal the plethysmograph around the nose and mouth as described by Burnard et al. (1965). Airflow was recorded at the mouth by means of a mercury electronics pneumotachograph (resistance 1.4 $\mathrm{cmH}_{2} \mathrm{O} / 1 / \mathrm{sec}$ ) and a Sierex E.M.T. 32 pressure transducer, and the output was electrically integrated to give tidal volume.

During a period of quiet breathing the above parameters were recorded on an Ampex Electromagnetic Tape Recorder (SP 300). When all the measurements had been made the tape was replayed through a LanElectronics 419B oscilloscope, and 10 consecutive quiet breaths were selected for further analysis. The pressurevolume and flow-volume loops for each breath were plotted by means of a Bryans X-Y auto-plotter and examples of these loops for one breath are shown in Fig. 1.

From the pressure-volume loop pulmonary compliance $\left(C_{L}\right)$ was calculated as the ratio between volume change and the corresponding oesophageal pressure change at points of no flow. Mean pulmonary resistance $\left(R_{L}\right)$ was calculated as the ratio between total pressure change and total flow change between points of equal 

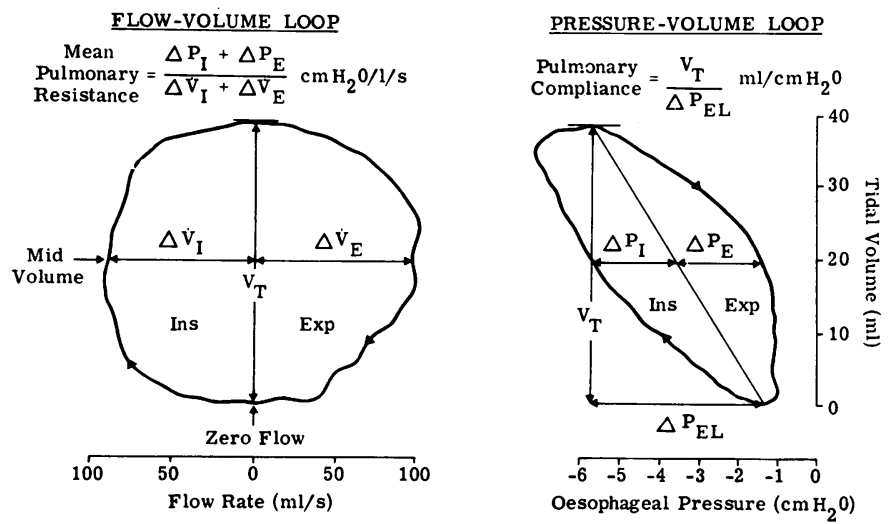

FIG. 1.-Pressure-volume and flow-volume loops plotted from a single breath. $\quad V_{\mathrm{T}}=$ tidal volume, $\triangle P_{\mathrm{EL}}=$ change in oesophageal pressure between points of zero flow, $\triangle P_{\mathrm{I}}$ and $\triangle P_{\mathrm{E}}=$ pressure required to overcome resistive forces at midinspiratory and midexpiratory volumes, respectively, $\triangle V_{\mathrm{I}}$ and $\triangle V_{\mathrm{E}}=$ flow rates at midinspiratory and midexpiratory volume, respectively.

volume midway in inspiration and expiration (see Fig. 1).

The reproducibility of these 10 measurements in each individual was such that the mean coefficients of variation $(\mathrm{SD} / \mathrm{mean})$ in the normal infants were $5.7 \%$ for $C_{L}$ and $7.9 \%$ for $R_{L}$, respectively, and in the cardiac infants they were $8.9 \%$ and $10 \cdot 1 \%$, respectively.

Thoracic gas volume (TGV) was measured by a plethysmographic technique. Airflow was interrupted at the mouth by suddenly inflating a balloon which was lying in the lumen of the pneumotachograph. As the infant continued to make respiratory efforts, mouth pressure and plethysmograph pressure changes were recorded on the tape recorder by means of S.E. Laboratories 1150/D5964 pressure transducers. TGV was then calculated by the method of Dubois et al. (1956) and corrected to end-expiratory level, and was therefore identical with functional residual capacity (FRC). This procedure was repeated 4 times and the mean result calculated.

The chest $x$-rays of the infants with congenital heart disease were examined by an experienced radiologist with regard to their pulmonary vasculature. They were presented to him on two separate occasions, in random order, without his knowledge of the physiological results or the fact that he was seeing the same films twice. The pulmonary vasculature was graded as being normal, oligaemic, or plethoric $1-3$, and the results of the grading for the individual infants are also shown in Table I.

\section{Results}

Normal infants. The relations between TGV and body weight, and between $\mathrm{C}_{\mathrm{L}}$ and TGV were both highly significant $(P<0.001)$ and are illustrated in Fig. 2 and 3. Not only was the $C_{L}-T G V$ relation linear but the regression line also passed through zero. The ratio of compliance to TGV,

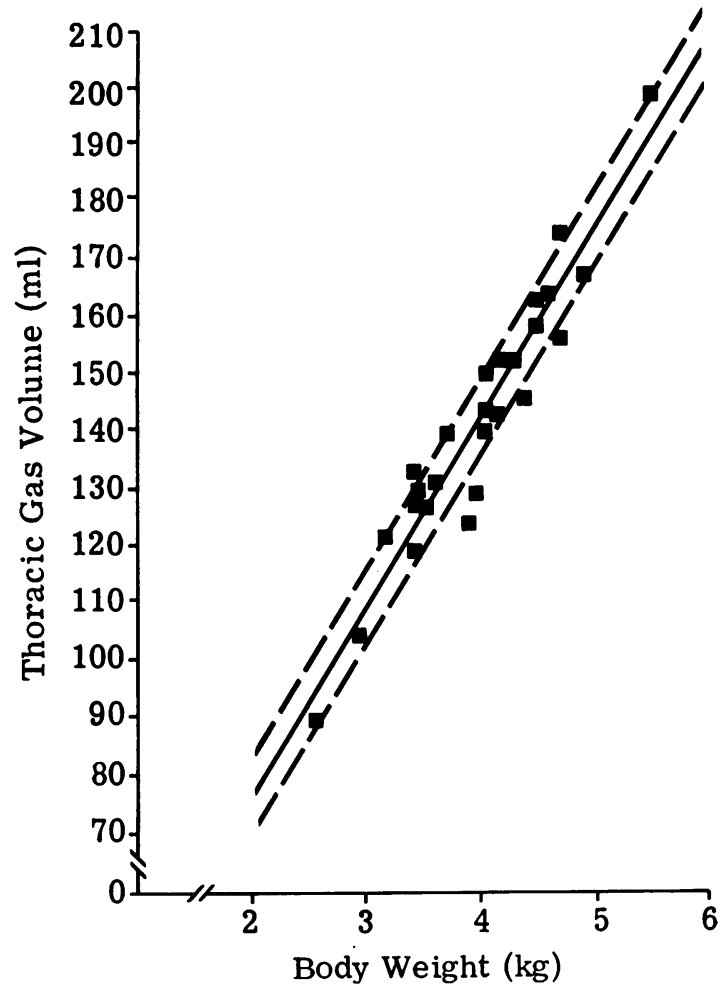

FIG. 2.-Relation between thoracic gas volume and body weight for normal infants. The calculated regression line for this and subsequent figures is shown together with \pm 1 standard error of the estimate of $y$ about the line. The regression equation is $y=32.47 x+11 \cdot 61(r=$ $0.955 ; P<0.001$ ). 


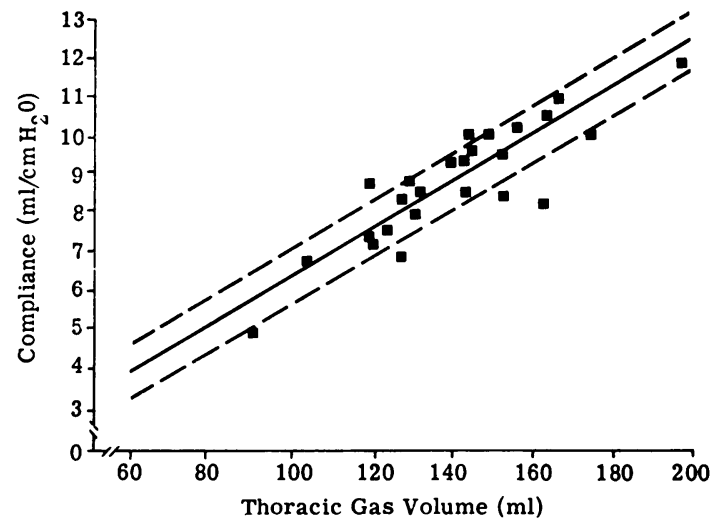

Fig. 3.-Relation between compliance and thoracic gas volume for normal infants. The regression equation is $y=0.0597 x+0.372(r=0.89 ; P<0.001)$.

termed specific compliance $\left(\mathrm{SC}_{\mathrm{L}}\right)$, was therefore constant and could be used to compare different individuals.

The coefficients of variation for the normal group of $\mathrm{TGV} / \mathrm{kg}$ and specific compliance were $5.1 \%$ and $7 \cdot 3 \%$, respectively, indicating that when TGV and compliance were corrected for body size there was only a narrow scatter in the normal results.

When conductance, the reciprocal of resistance, was related to TGV the relation was not significant $(P=0.1)$ in these infants. However, the range of values was small, the mean and 1 SD being $20 \cdot 6 \pm 3 \cdot 8\left(\mathrm{cmH}_{2} \mathrm{O} / 1\right.$. per sec $)$ for resistance.

Infants with congenital heart disease. The pulmonary function data from the individual infants with congenital heart disease are shown in Table II and the mean values are compared with those from the normal children in Table III.

The mean weight $(3.55 \mathrm{~kg})$ and length $(53.3$ $\mathrm{cm}$ ) were slightly below those for the normal infants. The mean frequency of breathing (72 $\pm 15 \cdot 2$ breaths/min) was increased, that of the normal infants being $58.4 \pm 12.6$ breaths $/ \mathrm{min}$. There was no significant difference between the tidal volume $/ \mathrm{kg}$ or the $\mathbf{R}_{\mathrm{L}}$ compared to the normal infants. The mean TGV for the cardiac infants was not significantly different from the normal infants when corrected for differences in body weight (Fig. 4).

When $C_{L}$ was related to $T G V$ the individual results often differed significantly from the normal (Fig. 5). The value given in Table III as the

TABLE II

Pulmonary Function Data From Infants with Congenital Heart Disease

\begin{tabular}{|c|c|c|c|c|c|c|c|}
\hline $\begin{array}{l}\text { Case } \\
\text { No. }\end{array}$ & $\begin{array}{l}\text { Weight } \\
\text { (kg) }\end{array}$ & $\begin{array}{l}\text { Length } \\
\text { (cm) }\end{array}$ & $\underset{\text { (breaths/min) }}{\text { Frequency }}$ & $\begin{array}{l}\text { Tidal Volume } \\
\text { (ml) }\end{array}$ & $\begin{array}{l}\text { TGV } \\
\text { (ml) }\end{array}$ & $\frac{\mathrm{Cl}_{\mathrm{L}}}{\left(\mathrm{ml} / \mathrm{cmH}_{2} \mathrm{O}\right)}$ & $\begin{array}{c}\mathrm{RL}_{\mathrm{L}} \\
\left(\mathrm{cmH}_{2} \mathrm{O} / 1 . \text { per sec) }\right.\end{array}$ \\
\hline $\begin{array}{r}1 \\
2 \\
3 \\
4 \\
5 \\
6 \\
7 \\
8 \\
9 \\
10 \\
11 \\
12 \\
13 \\
14 \\
15 \\
16 \\
17 \\
18 \\
19 \\
20 \\
21 \\
22 \\
23 \\
24 \\
25 \\
26 \\
27 \\
28\end{array}$ & $\begin{array}{l}3 \cdot 08 \\
4 \cdot 85 \\
3 \cdot 81 \\
3 \cdot 04 \\
3 \cdot 25 \\
4 \cdot 44 \\
3 \cdot 98 \\
2 \cdot 24 \\
3 \cdot 58 \\
3 \cdot 45 \\
3 \cdot 75 \\
4 \cdot 28 \\
3 \cdot 93 \\
5 \cdot 04 \\
3 \cdot 03 \\
5 \cdot 40 \\
3 \cdot 44 \\
3 \cdot 15 \\
2 \cdot 47 \\
4 \cdot 09 \\
2 \cdot 30 \\
3 \cdot 50 \\
4 \cdot 38 \\
3 \cdot 02 \\
2 \cdot 04 \\
3 \cdot 66 \\
2 \cdot 98 \\
3 \cdot 37\end{array}$ & $\begin{array}{l}48 \cdot 5 \\
61 \cdot 0 \\
55 \cdot 0 \\
49 \cdot 0 \\
54 \cdot 0 \\
54 \cdot 5 \\
59 \cdot 5 \\
44 \cdot 0 \\
52 \cdot 0 \\
56 \cdot 0 \\
54 \cdot 0 \\
61 \cdot 0 \\
54 \cdot 0 \\
61 \cdot 0 \\
48 \cdot 0 \\
68 \cdot 5 \\
53 \cdot 0 \\
48 \cdot 0 \\
50 \cdot 0 \\
54 \cdot 0 \\
48 \cdot 0 \\
50 \cdot 0 \\
57 \cdot 0 \\
48 \cdot 0 \\
46 \cdot 0 \\
53 \cdot 0 \\
52 \cdot 0 \\
53 \cdot 0\end{array}$ & $\begin{array}{r}56 \\
60 \\
60 \\
90 \\
85 \\
45 \\
80 \\
67 \\
85 \\
100 \\
65 \\
75 \\
57 \\
82 \\
75 \\
95 \\
85 \\
80 \\
80 \\
42 \\
80 \\
59 \\
70 \\
68 \\
96 \\
60 \\
94 \\
60\end{array}$ & $\begin{array}{l}18 \cdot 2 \\
42 \cdot 3 \\
37 \cdot 1 \\
20 \cdot 8 \\
30 \cdot 5 \\
64 \cdot 3 \\
56 \cdot 0 \\
35 \cdot 8 \\
32 \cdot 8 \\
30 \cdot 9 \\
32 \cdot 5 \\
52 \cdot 6 \\
47 \cdot 6 \\
41 \cdot 6 \\
35 \cdot 0 \\
39 \cdot 0 \\
31 \cdot 8 \\
29 \cdot 6 \\
25 \cdot 2 \\
61 \cdot 0 \\
26 \cdot 6 \\
20 \cdot 2 \\
35 \cdot 0 \\
33 \cdot 5 \\
18 \cdot 6 \\
38 \cdot 1 \\
28 \cdot 0 \\
31 \cdot 0\end{array}$ & $\begin{array}{r}95 \cdot 6 \\
180 \cdot 7 \\
133 \cdot 0 \\
99 \cdot 0 \\
117 \cdot 0 \\
147 \cdot 6 \\
136 \cdot 0 \\
79 \cdot 0 \\
- \\
- \\
- \\
163 \cdot 0 \\
160 \cdot 2 \\
163 \cdot 5 \\
118 \cdot 0 \\
166 \cdot 5 \\
135 \cdot 2 \\
92 \cdot 5 \\
- \\
135 \cdot 5 \\
75 \cdot 8 \\
150 \cdot 0 \\
93 \cdot 4 \\
71 \cdot 0 \\
133 \cdot 5 \\
110 \cdot 0 \\
115 \cdot 0\end{array}$ & $\begin{array}{r}2 \cdot 39 \\
5 \cdot 20 \\
5 \cdot 77 \\
3 \cdot 52 \\
3 \cdot 80 \\
13 \cdot 25 \\
10 \cdot 89 \\
6 \cdot 96 \\
4 \cdot 52 \\
7 \cdot 36 \\
3 \cdot 94 \\
8 \cdot 53 \\
7 \cdot 72 \\
9 \cdot 90 \\
7 \cdot 14 \\
5 \cdot 42 \\
5 \cdot 85 \\
4 \cdot 90 \\
5 \cdot 58 \\
10 \cdot 81 \\
3 \cdot 50 \\
2 \cdot 08 \\
9 \cdot 33 \\
5 \cdot 07 \\
2 \cdot 26 \\
8 \cdot 08 \\
5 \cdot 07 \\
5 \cdot 07\end{array}$ & $\begin{array}{l}27 \cdot 70 \\
35 \cdot 50 \\
17 \cdot 38 \\
30 \cdot 30 \\
22 \cdot 70 \\
18 \cdot 50 \\
14 \cdot 95 \\
18 \cdot 20 \\
24 \cdot 60 \\
21 \cdot 10 \\
29 \cdot 60 \\
20 \cdot 80 \\
31 \cdot 00 \\
15 \cdot 00 \\
21 \cdot 00 \\
13 \cdot 10 \\
37 \cdot 50 \\
21 \cdot 10 \\
18 \cdot 80 \\
27 \cdot 00 \\
25 \cdot 50 \\
43 \cdot 50 \\
17 \cdot 75 \\
22 \cdot 40 \\
35 \cdot 60 \\
17 \cdot 20 \\
33 \cdot 80 \\
40 \cdot 00\end{array}$ \\
\hline
\end{tabular}

Note: $\mathrm{TGV}$, thoracic gas volume; $\mathrm{C}_{\mathrm{I}}$, pulmonary compliances; $\mathbf{R}_{\mathrm{L}}$, mean pulmonary resistance. 
TABLE III

Mean Pulmonary Function Data from Normal Infants and Infants with Congenital Heart Disease

\begin{tabular}{|c|c|c|c|c|c|}
\hline \multirow{3}{*}{ Measurement } & \multicolumn{4}{|c|}{ Results } & \multirow{3}{*}{$\begin{array}{c}\text { Significance } \\
\text { of Difference } \\
\text { Between Means }\end{array}$} \\
\hline & \multicolumn{2}{|c|}{ Normal } & \multicolumn{2}{|c|}{ Cardiac } & \\
\hline & Mean & SD & Mean & SD & \\
\hline $\begin{array}{l}\text { Weight }(\mathrm{kg}) \\
\text { Length }(\mathrm{cm}) \\
\text { Frequency }(\mathrm{breaths} / \mathrm{min}) \\
\text { Tidal volume } / \mathrm{kg}(\mathrm{ml}) \\
\text { Thoracic gas volume } / \mathrm{kg}(\mathrm{ml}) \\
\text { Specific compliance }\left(\mathrm{ml} / \mathrm{cmH}_{2} \mathrm{O} \text { per } \mathrm{ml} \mathrm{TGV}\right) \\
\text { Mean pulmonary resistance }\left(\mathrm{cmH}_{2} \mathrm{O} / 1 . \text { per sec }\right)\end{array}$ & $\begin{array}{l}4 \cdot 01 \\
55 \cdot 8 \\
58 \cdot 4 \\
10 \cdot 39 \\
35 \cdot 5 \\
0 \cdot 062 \\
20 \cdot 57\end{array}$ & $\begin{array}{l} \pm 0 \cdot 66 \\
\pm 2 \cdot 97 \\
\pm 12 \cdot 6 \\
\pm 1 \cdot 27 \\
\pm 1 \cdot 78 \\
\pm 0 \cdot 0045 \\
\pm 3 \cdot 8\end{array}$ & $\begin{array}{l}3 \cdot 55 \\
53 \cdot 3 \\
72 \cdot 0 \\
9 \cdot 61 \\
34 \cdot 4 \\
0 \cdot 047 \\
23 \cdot 95\end{array}$ & $\begin{array}{l} \pm 0 \cdot 82 \\
\pm 5 \cdot 4 \\
\pm 15 \cdot 2 \\
\pm 2 \cdot 18 \\
\pm 3 \cdot 16 \\
\pm 0 \cdot 015 \\
\pm 7 \cdot 42\end{array}$ & $\begin{array}{l}P<0.001 \\
P=0.05 \\
P<0.001 \\
\text { NS } \\
\text { NS } \\
P<0.001 \\
\text { NS }\end{array}$ \\
\hline
\end{tabular}

NS, not significant.

mean $\mathrm{SC}_{\mathrm{L}}$ for the cardiac infants $\left(0.047 \mathrm{ml} / \mathrm{cmH}_{2} \mathrm{O}\right.$ per $\mathrm{ml}$ TGV) was the mean of those infants with left-to-right shunts and as a group they differ significantly from normal $(P<0.001)$. All the infants with an increase in both pulmonary artery pressure and flow had a reduction in $\mathrm{SC}_{\mathrm{L}}$ while in those infants with increased pulmonary pressure or flow alone the difference from normal was not so significant. The two infants with a decrease in both pulmonary pressure and flow had an increased $\mathrm{SC}_{\mathrm{L}}$.

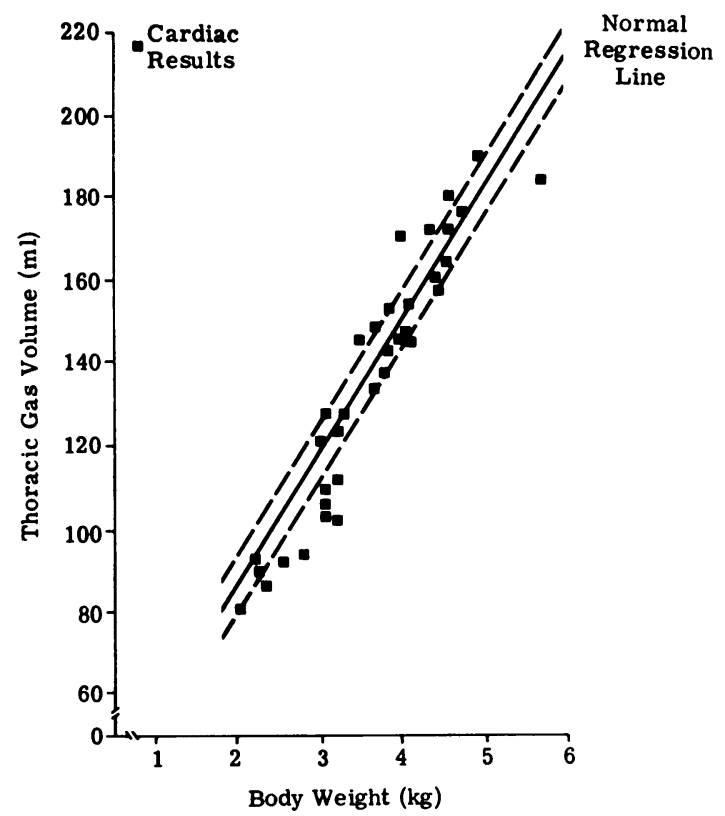

FIG. 4.-Relation between thoracic gas volume and weight for infants with congenital heart disease is shown superimposed on the regression line for normal infants.

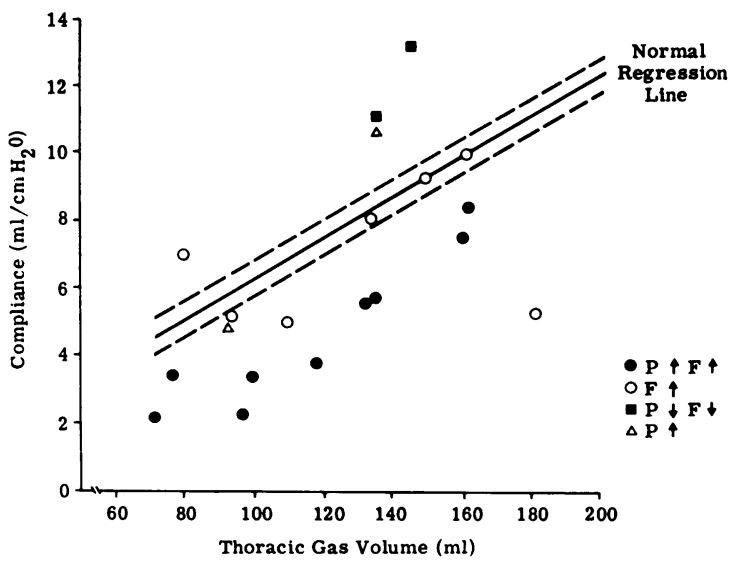

FIG. 5.-Relation between compliance and thoracic gas volume for infants with congenital heart disease is shown superimposed on the regression line for normal infants. $P=$ mean pulmonary artery pressure, $F=$ pulmonary flow.

When the $\mathrm{SC}_{\mathrm{L}}$ of the infants with congenital heart disease was related to mean pulmonary artery pressure or to pulmonary flow (Fig. 6a and 6b), no definite relation was found. But, when related to the product of pulmonary artery pressure and flow (the 'hyperkinetic index', Davies and Gazetopoulos, 1967) the relation was moderately significant $(\mathrm{P}<0.02$-Fig. 6c).

There was a very close relation between $S_{L}$ and the radiological grading of pulmonary plethora such that as the degree of plethora increased so the compliance of the lungs decreased (Fig. 7). Moreover, in the 6 infants who were studied before and after operation, as the radiological grading altered so did the compliance (Fig. 8). Cases 1 to 5 all had operations to reduce a left-to-right shunt and 


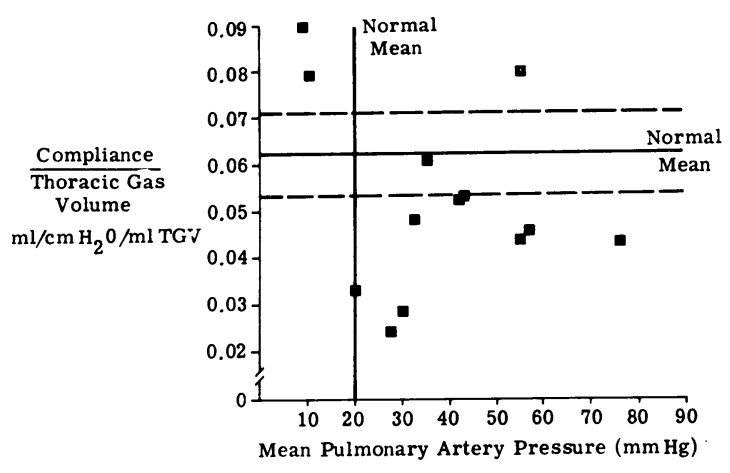

(a)

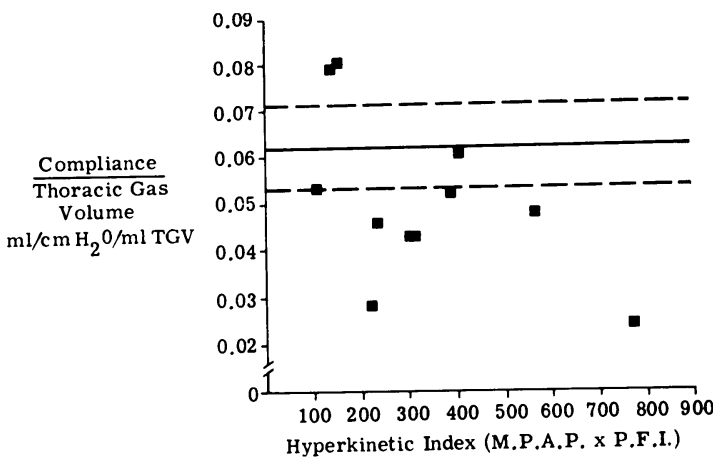

(c)

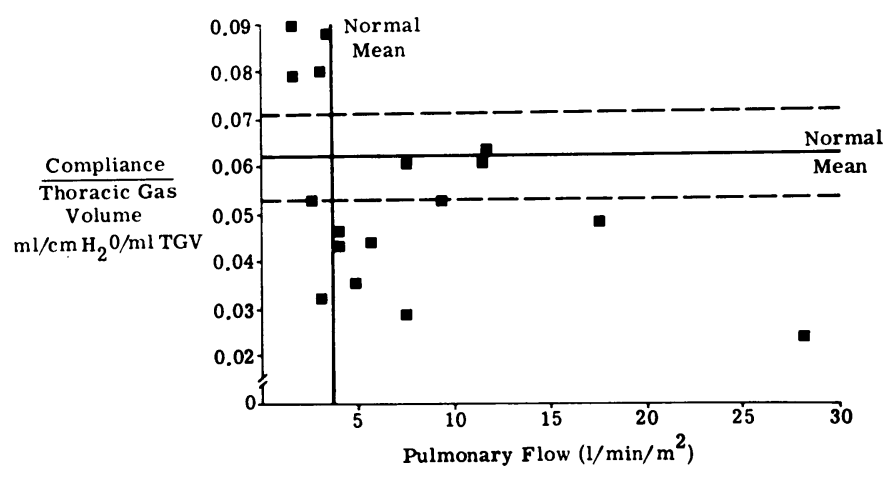

(b)

FIG. 6a, b, and c.-Specific compliance related (a) to mean pulmonary artery pressure, (b) to pulmonary flow and (c) to the product of pressure and flow (the hyperkinetic index), in infants with congenital heart disease. Horizontal lines represent the normal mean specific compliance $( \pm 2 S D)$. Solid vertical lines in $(a)$ and $(b)$ represent the mean normal pressure and flow, respectively.

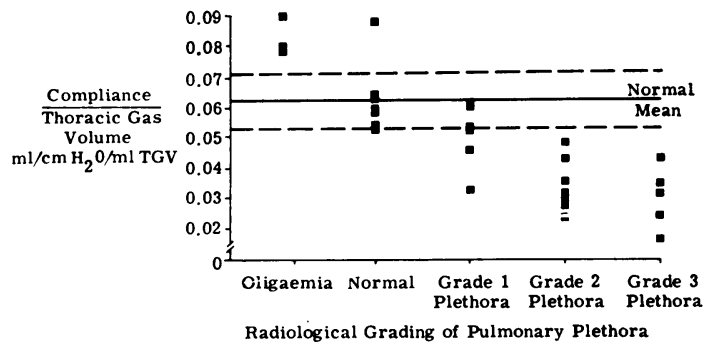

FIG. 7.-Specific compliance related to the radiological grading of pulmonary plethora. Solid line represents the mean normal specific compliance ( $\pm 2 S D$ ).

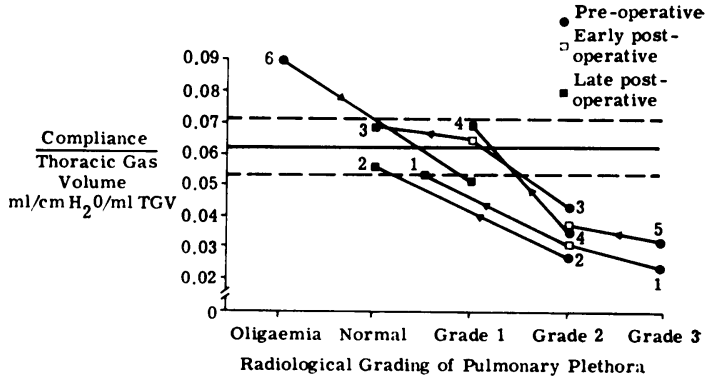

FIG. 8.-Change in the relation between specific compliance and radiological grading of pulmonary plethora in the 6 infants with congenital heart disease who were studied both before and after operation. The early postoperative study was done on the 5th and 6th day, and the late postoperative study was done between 4 to 6 weeks after the operation. Numbers 1 to 5 refer to children who had raised pulmonary flow initially, and number 6 refers to the child with reduced flow initially. 
in the 4 infants on whom measurements were made 4 to 6 weeks postoperatively both the radiological grading and the compliance had returned to within normal limits. In the one infant, Case 6 , who was studied before and after pulmonary valvotomy and reduction to right-to-left shunt, the compliance and radiological grading both improved. Thoracic gas volume was not significantly altered in these infants so that the changes in compliance were not due to volume.

\section{Discussion}

These results show that the compliance of the lungs often differs from normal in infants with congenital heart disease even when it is related to lung volume.

Normal results. The results obtained from the normal infants differ in some respects from those found in studies on younger infants (Cook et al., 1957; Swyer et al., 1960). The mean tidal volume and frequency were higher and the mean pulmonary resistance was lower but they are more similar to the results found in older infants (Phelan and Williams, 1969; Doershuk et al., 1970).

The larger tidal volume and respiratory rate noted in the present study was most likely due to the size of the dead space of the system which was approximately $20 \mathrm{ml}$. However, this method proved to be the simplest and most reproducible for the measurement of compliance and thoracic gas volume (corrected for the dead space) which were of primary interest to the present study.

The techniques used in the present study are identical with those used by Phelan and Williams (1969), and the similarity of the results suggests that differences in techniques are in fact among the main reasons for the wide scatter of normal results quoted in the literature. The very good reproducibility and narrow scatter both within the individual and the normal group results obtained in the present study indicate that this method could be used for comparisons between the infants with congenital heart disease and the normal control group.

The highly significant correlation between TGV and body weight (Fig. 2) is in agreement with many other workers, and the mean value $35.5 \mathrm{ml} / \mathrm{kg}$ is comparable with that quoted by Phelan and Williams (1969), $31.5 \mathrm{ml} / \mathrm{kg}$, Doershuk et al. (1970), $32.4 \mathrm{ml} / \mathrm{kg}$; and Auld et al. (1963) 35.8 $\mathrm{ml} / \mathrm{kg}$. Similarly, the significant relation between $\mathrm{C}_{\mathrm{L}}$ and TGV (Fig. 3) has been found by other workers. The mean $S C_{\mathrm{L}}$ of $0.062 \mathrm{ml} / \mathrm{cmH}_{2} \mathrm{O}$ per $\mathrm{ml}$ TGV is a little higher than that quoted by Phelan and Williams (1969) of $0.056 \mathrm{ml} / \mathrm{cmH}_{2} \mathrm{O}$ per $\mathrm{ml} \mathrm{TGV}$, but it is within the generally accepted range.

The fact that there was no significant relation between conductance and TGV was probably due to the relatively small size range of the infants studied because a good correlation was obtained by Doershuk et al. (1970) over a much larger range. However, the absolute value for pulmonary resistance (or conductance) was within the range found by other workers for infants (Swyer et al., 1960; Krieger, 1963).

Infants with congenital heart disease. The effect of altered pulmonary haemodynamics upon the mechanical behaviour of the lungs has been investigated by several workers since it was originally suggested by von Basch (1887) that vascular congestion in the lungs might cause a stiffening of the parenchyma, and by Eisenmenger (1898) that in ventricular septal defect the pulmonary circulation was overfilled and the lungs stiffer. However, virtually all the results quoted to date have been obtained from adults and older children (Saxton et al., 1956; Davies et al., 1962; Davies and Gazetopoulos, 1967). It has been possible to find only one reference (Wallgren et al., 1960) which quotes figures for infants, and of the 25 infants they studied only 9 were less than 6 months of age. It is therefore of some significance that the results obtained in the present study on neonates and infants, whose pulmonary mechanics and circulation are presumably more labile, are very similar to those quoted for older children and adults

Wallgren et al. (1960) suggested that the reduction in compliance found in the presence of left-toright shunt might be due to a reduction in the aerated lung volume. The findings of the present study that TGV was not reduced in infants with congenital heart disease is in agreement with Davies and Gazetopoulos (1967) who found that the measured FRC in 38 adult patients with various forms of left-to-right shunt did not differ significantly from the predicted FRC. Wallgren et al. (1960) did not measure lung volume during their study and the present findings tend to disprove their theory.

The good correlation between compliance and TGV (Fig. 3) enabled a comparison to be made between the normal infants and the cardiac infants. The reduced $\mathrm{SC}_{\mathrm{l}}$ in the infants with left-to-right shunts is in agreement with Wallgren et al. (1960), Davies et al. (1962), and Ohnishi (1970) in older subjects. The lack of significant correlation between specific compliance and pulmonary arterial pressure or flow in the present study confirms the previous findings in older subjects (Saxton et al., 
1956; Davies et al., 1962; Davies and Gazetopoulos 1967; Wallgren et al., 1960). The explanation remains uncertain and could even be coincidental. It could be suggested that interstitial changes such as incipient or actual pulmonary oedema could have reduced the compliance but the fact that the $\mathrm{C}_{\mathrm{L}}$ was increased in the two cases with a reduction in pulmonary pressure and flow makes the hypothesis unlikely. Moreover, one would not expect the thoracic gas volume and pulmonary resistance to be normal in the face of major interstitial changes.

It has been suggested that an increase in the actual blood volume present in the pulmonary vessels may be the major factor in altering the mechanics of the lungs. Mills (1949) found that altering the pulmonary blood volume in adult subjects altered the vital capacity. Harada (1959) studied healthy adult dogs before and after lung resection and found a positive correlation between the postoperative changes in pulmonary blood volume and decrease in the effective pulmonary compliance.

Bondurant, Hickam, and Isley (1957) reported a rapid decrease in compliance after the induction of acute central venous congestion in normal human subjects. The findings of the present study that the radiological grading of the pulmonary vasculature correlated closely with $\mathrm{SC}_{\mathbf{L}}$ suggests that the actual blood volume is an important factor in altering lung mechanics in heart disease. As the lungs became more plethoric so the specific compliance fell and vice versa. Moreover, the specific compliance and pulmonary vascularity changed in the appropriate direction as a result of surgery. Haughton (1968) studied 3 adults with pulmonary stenosis and found that the compliance was high before operation and fell strikingly after valvotomy.

In conclusion therefore, infants with congenital heart disease have normal lung volumes and resistance to air flow, but a disturbance of the elastic properties of their lungs. When the lungs are plethoric with high pulmonary artery pressure and increased blood flow they are stiffer than normal. When they are oligaemic with low pulmonary artery pressure and reduced blood flow their elasticity is increased. The elastic properties can be changed acutely by surgery. It is postulated that the changes in elastic properties are related to changes in pulmonary capillary blood volume.

I thank Drs. A. P. Norman and D. R. Harvey for allowing me to study normal infants at Queen Charlotte's Maternity Hospital, and Dr. G. Simons for his interpretation of the $x$-rays; also Dr. S. Godfrey for his help and advice; and Miss G. Earle and the staff of the
Paediatric Unit at the Brompton Hospital for their assistance.

The author was in receipt of a grant from The Medical Research Council during the period of this study.

\section{REFERENCES}

Auld, P. A. M., Nelson, N. M., Cherry, R. B., Rudolph, A. J., and Smith, C. A. (1963). Measurement of thoracic gas volume in the newborn infant. fournal of Clinical Investigation, 42, 476.

von Basch, S. S. K. (1887). Ueber eine Function des Capillardruckes in den Lungenalveolen. Wiener Medizinische Blätter, 10, 465.

Bondurant, S., Hickam, J. B., and Isley, J. K. (1957). Pulmonary and circulatory effects of acute pulmonary vascular engorgement in normal subjects. Fournal of Clinical Investigation, 36, 59.

Borst, H. G., Berglund, E., Whittenberger, J. L., Mead, J., McGregor, M., and Collier, C. (1957). The effect of pulmonary vascular pressures on the mechanical properties of the lungs of anesthetized dogs. Fournal of Clinical Investigation, 36,1708.

Burnard, E. D., Grattan-Smith, P., Picton-Warlow, C. G., and Grauaug, A. (1965). Pulmonary insufficiency in prematurity. Australian Paediatric fournal, 1, 12.

Cook, C. D., Mead, J., Schreiner, G. L., Frank, N. R., and Craig, J. M. (1959). Pulmonary mechanics during induced pulmonary edema in anesthetized dogs. Fournal of Applied Physiology, 14, 177.

Cook, C. D., Sutherland, J. M., Segal, S., Cherry, R. B., Mead, J., McIlroy, M. B., and Smith, C. A. (1957). Studies of respiratory physiology in the newborn infant. III. Measurements of mechanics of respiration. Fournal of Clinical Investigation, 36, 440.

Cross, K. W. (1949). The respiratory rate and ventilation in the newborn baby. Fournal of Physiology, 109, 459.

Davies, H., and Gazetopoulos, N. (1967). Lung function in patients with left-to-right shunts. British Heart fournal, 29, 317.

Davies, H., Williams, J., and Wood, P. (1962). Lung stiffness in states of abnormal pulmonary blood flow and pressure. British Heart fournal, 24, 129.

Doershuk, C. F., Downs, T. D., Matthews, L. W., and Lough, M. D. (1970). A method for ventilatory measurements in subjects 1 month to 5 years of age: normal results and observations in disease. Pediatric Research, 4, 165.

Dubois, A. B., Botelho, S. Y., Bedell, G. N., Marshall, R., and Comroe, J. H., Jr. (1956). A rapid plethysmographic method for measuring thoracic gas volume: a comparison with a nitrogen washout method for measuring functional residual capacity in normal subjects. Fournal of Clinical Investigation, 35, 322.

Eisenmenger, V. (1898). Ursprung der Aorta aus beiden Ventrikeln beim Defect des Septum ventriculorum. Wiener Klinische Wochenschrift, 11, 26.

Harada, K. (1959). Changes in pulmonary compliance before and after lung resection and relations between dynamics of pulmonary circulation and pulmonary compliance. Tokushima Fournal of Experimental Medicine, 5, 377.

Haughton, V. (1968). Changes in pulmonary compliance in patients undergoing cardiac surgery. Diseases of the Chest, 53, 617.

Klaus, M., Tooley, W. H., Weaver, K. H., and Clements, J. A. (1962). Lung volume in the newborn infant. Pediatrics, 30. 111.

Krieger, I. (1963). Studies on mechanics of respiration in infancy. American Fournal of Diseases of Children, 105, 439.

Mills, J. N. (1949). The influence upon the vital capacity of procedures calculated to alter the volume of blood in the lungs. Fournal of Physiology, 110, 207.

Ohnishi, A. (1970). Lung function in children with congenital heart disease. Acta Paediatrica faponica, 12, 75.

Phelan, P. D., and Williams, H. E. (1969). Ventilatory studies in healthy infants. Pediatric Research, 3, 425.

Saxton, G. A., Jr., Rabinowitz, M., Dexter, L., and Haynes, F. (1956). The relationship of pulmonary compliance to pulmonary vascular pressures in patients with heart disease. fournal of Clinical Investigation, 35, 611 .

Swyer, P. R., Reiman, R. C., and Wright, J. J. (1960). Ventilation and ventilatory mechanics in the newborn. Fournal of Pediatrics, 
Wallgren, G., Geubelle, F., and Koch, G. (1960). Studies of the mechanics of breathing in children with congenital heart lesions. Acta Paediatrica, 49, 415.

\section{Addendum}

Since this work was completed, Griffin et al. (1972) have published their findings of similar studies in infants with congenital heart disease and have come to similar conclusions.

\section{REFERENCE}

Griffin, A. J., Ferrara, J. D., Lax, J. O., and Cassels, D. E. (1972). Pulmonary compliance. American fournal of Diseases of Children, 123, 89.

Correspondence to Dr. G. Howlett, Paediatric Department, Institute of Diseases of the Chest, Fulham Road, London SW3. 